Project Title: Measurement of Radon, Thoron, Isotopic Uranium and Thorium to Determine Occupational and Environmental Exposure and Risk at Fernald Feed Material Production Center

Covering Period: April 1, 2000 through October 31, 2002

Date of Report: October 31, 2002

Recipient: New York University School of Medicine

Address: Dept. Environmental Medicine, 550 First Avenue, New York, NY 10016

Award Number: DE-FG07-97ER62522 EMSP 74050

Contact: Principal Investigator: Naomi H. Harley, Ph.D. Institution: New York University School of Medicine

Dept. Environmental Medicine, 550 First Avenue, New York, NY 10016

Phone:(212)263-5287

Email: naomi.harley@med.nyu.edu

Project Team: Dr. Roland Hirsch, Mr. Mark Gilbertson

\title{
Project Objectives:
}

There are three basic research objectives.

1. To develop an accurate personal and area radon/thoron $\left({ }^{222} \mathrm{Rn} /{ }^{220} \mathrm{Rn}\right)$ detector for accurate measurement of the exposure to low airborne concentrations of these gases during remediation at Fernald. These are to be used to determine atmospheric dispersion and exposure to radon and thoron prior to and during retrieval and removal of the $4000 \mathrm{Ci}$ of radium $\left({ }^{226} \mathrm{Ra}\right)$ in the two silos at Fernald .

2. To develop a miniature personal (or area) aerosol particle size sampler that will operate continuously for weeks of continuous sampling under adverse conditions such as outdoors. Aerosol particle size is the major determinant of lung dose and without a measurement of the inhaled aerosol particle size accurate lung dosimetry cannot be obtained. No DOE site, with the exception of Fernald, is measuring the inhaled particle size spectrum for dosimetric purposes.

3. To develop the sequential radiochemistry necessary to measure any environmental sample (soil or water) for ${ }^{228,230,232} \mathrm{Th},{ }^{226,228} \mathrm{Ra},{ }^{234,235,238} \mathrm{U}$ and ${ }^{210} \mathrm{~Pb}$. To utilize the radiochemistry to accurately trace and delineate these nuclides in the environment.

\section{Background:}

Fernald has considerable radium and thorium-230 waste and was the largest storage 
facility in the United States for thorium-232. The site is now undergoing remediation and the land will eventually be returned to the State of Ohio. The plant was located at a relatively remote location as all of the historic centers involved in the production or processing of nuclear material for weapons or nuclear reactors.

One of the primary operations at the Fernald site was separation of uranium from the naturally occurring uranium bearing ore. Natural uranium supports a chain of 13 radionuclides that includes several long lived members, namely radium-226 (1600 y), thorium-230 $\left(8 \times 10^{4} \mathrm{y}\right)$, and lead-210 (22 y ). In the ore all the nuclides are in equilibrium, i.e., the specific radioactivity $(\mathrm{Ci} / \mathrm{gm})$ of each member is the same. Following the uranium extraction via a solvent, the radium was precipitated as solid radium barium sulfate, similar to a fine grained white sand. The viscous residue solution containing thorium 230 and lead-210 was disposed of in onsite raffinate pits.

The ${ }^{226} \mathrm{Ra}$ decays directly to ${ }^{222} \mathrm{Rn}$ and its short lived decay products. There is always some normal off gassing of radon from the silos and as the ${ }^{226} \mathrm{Ra}$ is transferred out of the silos the atmospheric concentrations and the dispersion of the radon must be determined. It is well documented that the actual lung dose and risk from radon is not directly from the gas, but from the deposition of its particulate short lived decay products on the lining of the bronchial airways (Harley et al. 1996, NCRP 1984, NAS 1999). The decay products attach to the natural aerosol particles and this particle size distribution determines the ultimate lung dose.

Because Fernald had also been a storage site for thorium-232, the potential for exposure to its gaseous decay product radon-220 (thoron) exists. Thorium-232 supports a decay chain of 10 radionuclides that include radon- 220 .

For disposal, the thorium-230 in the raffinate pits is dug and first taken to a large on-site soil dryer. The relocation of this material to Utah involves drying at high temperature to remove any volatile organic material in the waste. During the drying there is the potential for release and inhalation of the alpha emitter thorium-230, and a need to measure air concentrations and particle size.

$\mathrm{As}^{226} \mathrm{Ra}$ is removed for ultimate burial in Utah, there is a need to accurately assess the airborne concentration and dispersion of radon and the particle size of the aerosolized radon decay products. As material is dug from the raffinate pits and dried there is a need for concentration measurements and aerosol particle size sampling to assess its dispersion and consequent lung dose.

\section{Status:}

Personal and Area ${ }^{222} \mathrm{Rn}$ (radon) and ${ }^{220} \mathrm{Rn}$ (thoron) Measurements

With the exception of the detector developed for Fernald, there is presently no other 
instrument to measure both radon and thoron gas simultaneously, and in duplicate, in a miniature personal or area monitor. This detector measures even very low outdoor environmental concentrations of both gases with proven accuracy. To assess thoron bronchial dose, the decay products of thoron ${ }^{212} \mathrm{~Pb}$ and ${ }^{212} \mathrm{Po}$, are usually measured (Schery 1985, 1990, Schery and Zarcony 1985, Harley and Chittaporn, 2000, Harley et al. 2000), and ${ }^{220} \mathrm{Rn}$ concentrations are also estimated from these decay products.

Thoron gas itself is rarely measured, because of the difficulty in measuring an alpha particle emitting gas with a very short half life ( $\mathrm{t} 1 / 2=55 \mathrm{secs})$. The measurement of the two gases normally requires expensive, laboratory, real time instrumentation with various types of decay chambers to permit a difference in signal with and without the ${ }^{220} \mathrm{Rn}$ (Israel, 1964, NCRP, 1987). The NYU passive alpha track detector measures the integrated signal from the alpha decay of thoron gas, over any time period, depending upon the exposure assessment needs in an inexpensive miniature passive field detector.

The ${ }^{222} \mathrm{Rn}$ and ${ }^{220} \mathrm{Rn}$ personal monitor was originally designed to use alpha track detection film in 3 separate chambers using different entry diffusion barriers for signal differentiation between the two gases. A conducting foam, directly above each chamber excludes the solid decay products and permits only radon or thoron gas passage. The monitor shape is trilobed (similar to a cloverleaf) with a face dimension of $5 \mathrm{~cm}$. across chambers and a thickness of $1 \mathrm{~cm}$., weight 26 grams. It is molded from conducting $\mathrm{ABS}(\mathrm{CNi})$ plastic, i.e., plastic with embedded nickel coated carbon fibers. The nuclear track film used for detection of the alpha particles emitted within each chamber is a $9 \times 9 \mathrm{~mm}$ square solid state nuclear track film (CR-39). The pristine film background is 5 to 15 alpha particle tracks depending upon the batch and the entire film area is counted. A photo of both the 3 and 4 chamber detectors is shown in Figure 1 . The 4 chamber detector is now used exclusively.

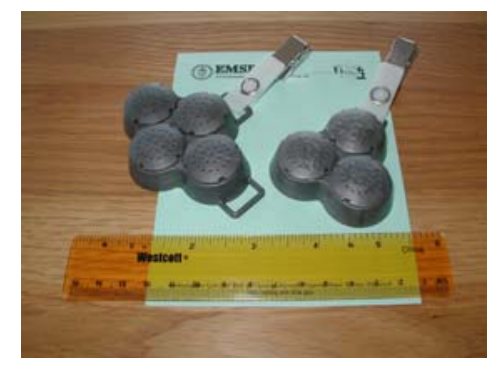

Figure 1. Three and 4 chamber radon/ thoron detector

The unit displays no charge artifacts and thus the calibration is constant in all situations. The efficiency for ${ }^{222} \mathrm{Rn}$ is ( 0.009 Track per $\mathrm{Bq} \mathrm{m}^{-3}$ day) $(0.32$ Track per $\mathrm{pCi} / \mathrm{L}$ day $)$ and the lower limit of detection is $220 \mathrm{~Bq} \mathrm{~m}^{-3}$ day $(6 \mathrm{pCi} / \mathrm{L}$ day $)$ using a video imaging system for 
counting the alpha particle tracks. The efficiency for thoron is 0.013 Track per Bq $\mathrm{m}^{-3} \mathrm{day},(0.48$ Track per $\mathrm{pCi} / \mathrm{L}$ day) and the lower limit of detection is $1100 \mathrm{~Bq} \mathrm{~m}^{-3}$ day $(30 \mathrm{pCi} / \mathrm{L}$ day $)$. The difference in efficiency for the 2 gases is due to the change in volume of the detection chamber with the diffusion barrier in place. Each chamber has a conducting foam entrance filter to prevent entry of the decay products of either radon isotope, and an "O" ring seal to prevent leakage of thoron gas around the diffusion barrier. We have demonstrated using exposures to very high thoron concentrations that no thoron entry to the radon chamber takes place.

Once we began measurement of both radon and thoron, it became clear that thoron was ubiquitous and always present in the gas signal. This occurs at all sites not only at Fernald but at our quality control site at the National Weather Service site in Central Park, Manhattan and any other location indoors or out where measurements are made. The original 3 chamber version was then modified to contain 4 chambers so that duplicate measurements of both gases could be made to obtain the precision of the measurements. When measuring the total gas radon concentration, thoron concentrayion must always be known, otherwise the gas measurement is ambiguous. The newly fabricated 4 chamber version has been in use for about 2 years.

Various diffusion barriers were tested for their efficiency in permitting radon entry while inhibiting thoron entry. The most appropriate barrier film for our purposes is 3 mil aluminized Mylar, and this is now used in all the ${ }^{222} \mathrm{Rn}$ measurements.

After exposure in our radon and thoron test chambers, or in the field, the CR-39 alpha track film is etched in $6 \mathrm{~N} \mathrm{KOH}$ overnight to reveal the alpha particle tracks as shallow pits. The tracks are scored either visually after enlarging the 9x9 $\mathrm{mm}$ area with a microfiche reader and printing to a standard "hard copy" paper image (about 23X), or by image analysis. The image analysis technique scores all tracks on the 9x9 mm film directly, using an Olympus Zoom microscope, and a Data Translation frame grabber and image analysis program (GlobalLab Image/2). Track counting is normally performed using image analysis with about 10 to $20 \%$ of samples also scored visually for QC. Pristine nuclear track film and exposed positive controls are etched with each batch of research or field samples for QC. Extensive quality control accompanies all measurements. The detectors are submitted to all intercomparison exercises both at the USDOE EML laboratory (EML 1997) and the commercial Bowser Morner radon intercomparisons. Our results have never differed from the intercomparison target value by more than $10 \%$.

\section{Results}

Twenty five Cloverleaf or 4 chamber detectors have been placed outdoors surrounding the radium containing silos at Fernald since May 2000. Most of the measurements show normal background radon concentration, however, downwind of the silos there is a somewhat elevated

${ }^{222} \mathrm{Rn}$ concentration. The radon and thoron data are shown in Figure 2 and 3. The ${ }^{222} \mathrm{Rn}$ concentration at this location averaged about $50 \mathrm{~Bq} \mathrm{~m}^{-3}$ over the period May 2000 to April 2001. The ${ }^{220} \mathrm{Rn}$ concentration averaged about $15 \mathrm{~Bq} \mathrm{~m}^{-3}$ during the same period, or about $25 \%$ of the total signal. A photo of the silos is shown in Figure 4, and the temporary concrete vault for 
storage during transit process to Utah is shown in figure5. One of the radon/ thoron detectors located around the silo perimeter is shown in figure 6 .

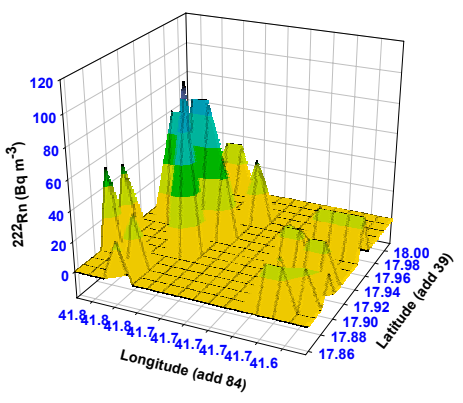

Figure 2. Radon concentration on top of around the radium silos

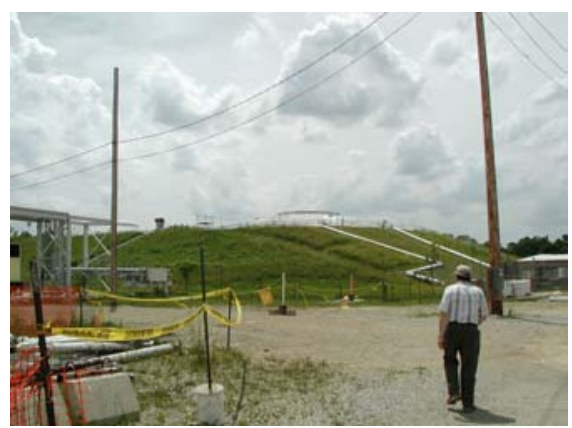

Figure 4. The radium silos at Fernald

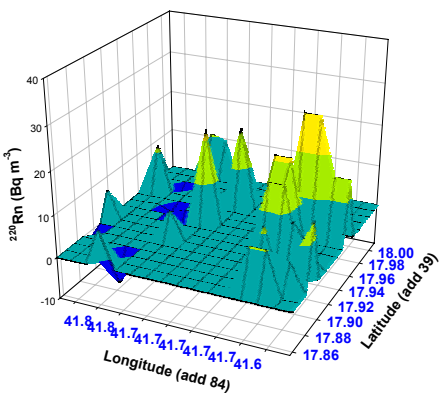

Figure 3. Thoron concentration on top of and around the radium silos

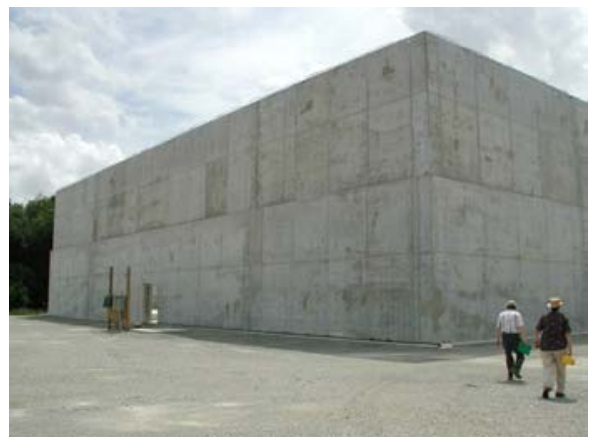

Figure 5. Temporary concrete vault for Radium storage during transit to Utah 


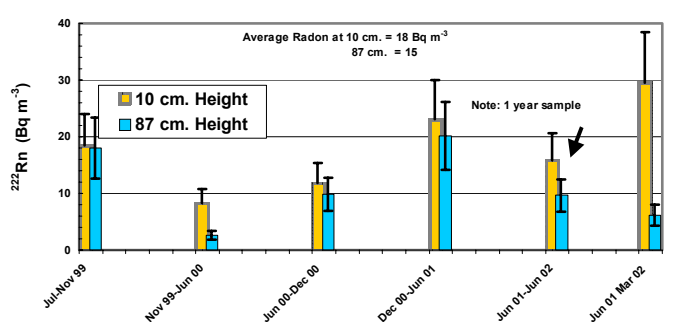

Figure 7. Radon at 10 and $87 \mathrm{~cm}$. Height at NYC National Weather Service Site

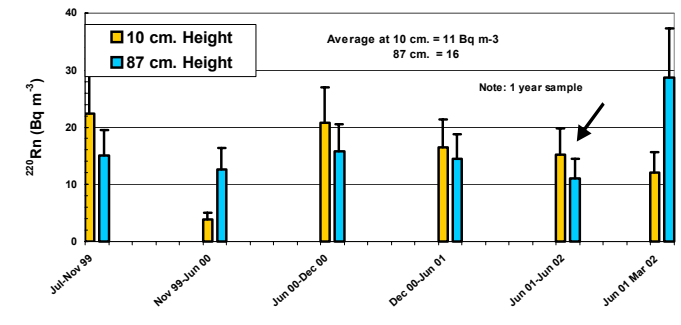

Figure 8. Thoron at 10 and $87 \mathrm{~cm}$. Height at NYC National Weather Service Site

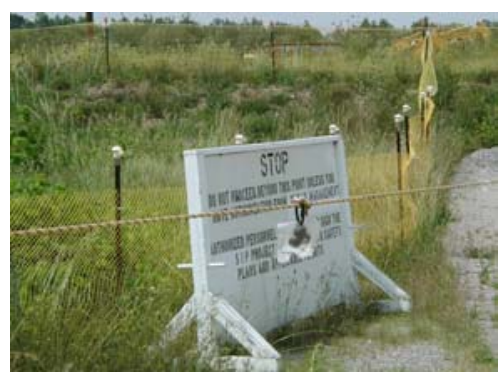

Figure 6. Radon/ Thoron detector at silo perimeter 
Measurements for quality control are made in the National Weather Service site in Central Park, Manhattan. The detectors are located at $10 \mathrm{~cm}$. and $87 \mathrm{~cm}$. above bare earth in two locations within the fence. These data are shown in Figure 7 and 8. In these measurements ${ }^{220} \mathrm{Rn}$ almost always exceeds the ${ }^{222} \mathrm{Rn}$.

It is of significance that the detectors measured both radon and thoron simultaneously, at normal background concentrations. The thoron was in most cases a significant fraction of the total gas signal or exceeded the ${ }^{222} \mathrm{Rn}$ concentration. This suggests that historic measurements of "radon" made in homes with detectors capable of permitting thoron gas entry could have provided an effective ${ }^{222} \mathrm{Rn}$ concentration that was somewhat higher than actual due to the confounding influence of ${ }^{220} \mathrm{Rn}$. Because the dose from thoron decay products is about a factor of five less than that from radon per unit exposure, the health effects from survey data have surely been overestimated.

\section{Particle Size Sampler}

There is presently no sampler available commercially or otherwise that will sample for up to 2 months in severe weather conditions and provide particle size distribution information on the natural aerosol at normal environmental concentrations. This personal sampler $(4 \mathrm{~cm}$. 22 $\mathrm{cm}$. diam./height, weight $55 \mathrm{gms}$.) has been developed for personal or area use specifically for Fernald. The present configuration is a commercial sampler head modified to contain a $\mathrm{ZnS}$ alpha phosphor inlet impaction stage, followed by four, very fine mesh stainless steel screen filters, and an exit Millipore filter to collect all residual particles. A low flow pump (4-6 lpm) draws the atmosphere sampled through the sampler for periods of up to 2 months for an integrated particle size sample. Six units have sampled outdoors at the USDOE Fernald site for about 2 years. The locations are, on top of and between the two ${ }^{226} \mathrm{Ra}$ storage silos, near the raffinate waste pits, and several portable locations during the decontamination process. Radon and thoron measurements are always made simultaneously with the particle size measurements using the 4 chamber alpha track detector. Two background locations in New Jersey are monitored synoptically, and four detectors are located in the New York City National Weather Service site in Central Park for quality control.

The short lived ${ }^{222} \mathrm{Rn}$ decay products attach to the ambient aerosol, and ultimately decay to ${ }^{210} \mathrm{~Pb} /{ }^{210} \mathrm{Po}$ which are used as the particle tracer. The ${ }^{210} \mathrm{Po}$ on the 6 filtration stages are alpha 
counted in our ultra low background scintillation counters ( 5 counts per day) and a deconvolution program estimates the particle size distribution from the measurements. Extensive calibrations were performed using standard latex particles, and freshly formed (unattached) ${ }^{222} \mathrm{Rn}$ decay products, to determine the deposition characteristics of the sampler over the size range from ultrafine $(<1 \mathrm{~nm})$ to micrometer sized particles. Three size modes are evident in all outdoor field samples, an ultrafine, a small sized (100-200 nm), and a micron sized mode.

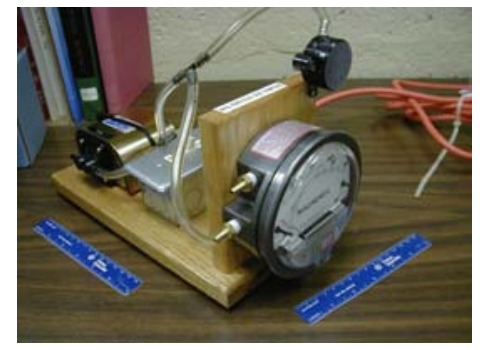

Figure 9. Aerosol particle size sampler

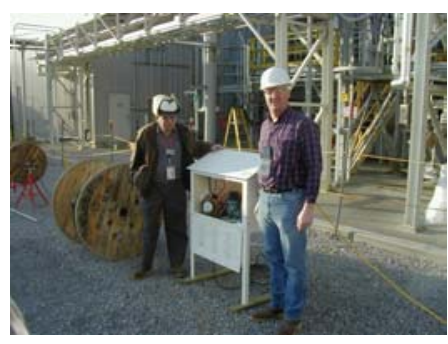

Figure 10. Aerosol sampler on site at Fernald

The size distribution on top of the radium silos at Fernald and outdoors at a research home in New Jersey remains the same over seasonal intervals at each site. The median diameter is about $400 \mathrm{~nm}$ at Fernald and about $200 \mathrm{~nm}$ in New Jersey. However, the seasonal concentration of ${ }^{210} \mathrm{~Pb} /{ }^{210} \mathrm{Po}$ varies by a factor of 2 with the highest concentrations in winter, 
1700 vs $600: \mathrm{Bq} / \mathrm{m} 3$ at Fernald, and 650 versus $300: \mathrm{Bq} / \mathrm{m} 3$ in New Jersey. The size distribution of the ultrafine or unattached fraction of the decay products (about 1 to $5 \mathrm{~nm}$ ) also varies seasonally with larger median diameter occurring in colder season. The reason for these differences is likely due to the well known increase in the number of temperature inversions during winter.

The particle size sampler is shown in Figure 9, and on site at Fernald in figure 10.

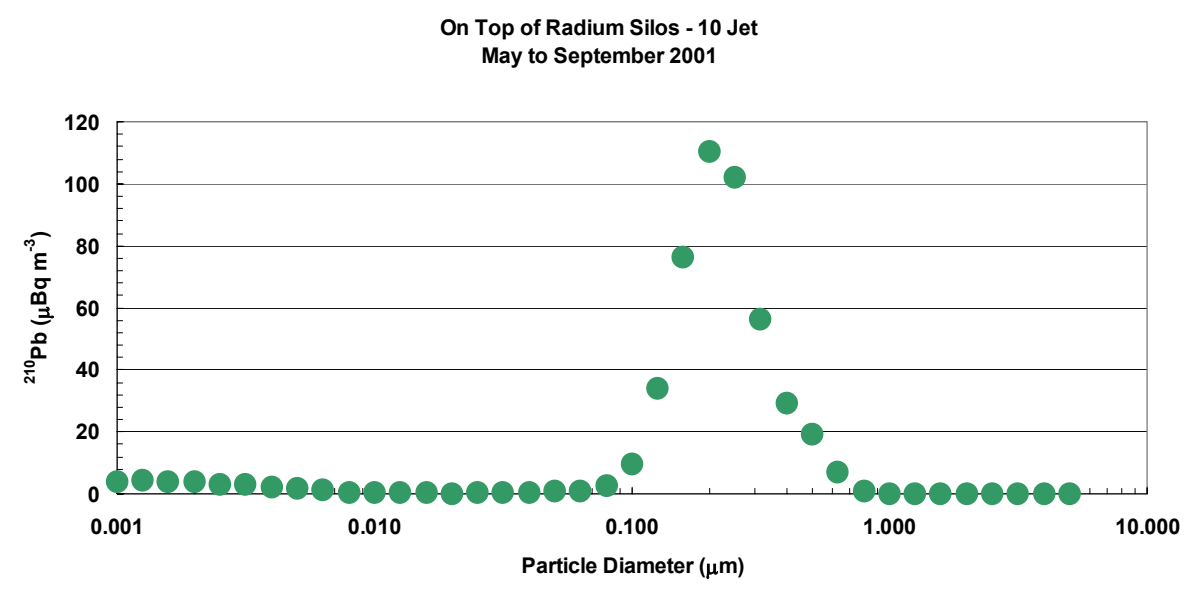

Figure 11. Particle size distribution measured on top of silos

This particle size sampler is currently being modified and molded in conducting plastic by the company that provides our radon/ thoron detector. The new version will have additional fine mesh screen filters to give higher resolution to the particle size spectrum. Within the next year, this inexpensive sampler it will be available to any DOE site for size sampling. This is to be encouraged and we are attempting to encourage the appropriate radiological persons at other sites. Without the size information it is not possible to estimate lung dose with accuracy. 
The particle size distribution data measured by the sampler between the silos along with the comparison quality control site in New jersey is shown in Figure 11 and 12.

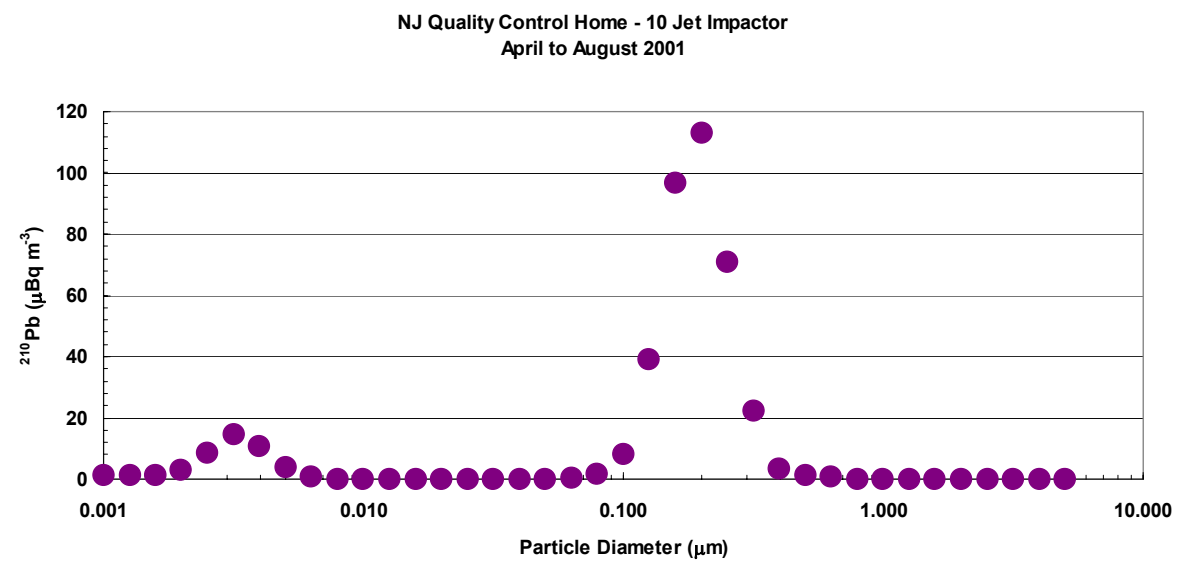

Figure 12. Particle size distribution measured outdoors at a NJ quality control home

\section{Radiochemical Soil analysis}

This is in progress as our collaborator at the USDOE, EML laboratory had difficulty in obtaining equipment for this part of the research. Soil samples are extremely difficult to obtain from Fernald as there are very strict rules about sampling and removal of any material. However, historic soil samples were obtained from the perimeter of the silos for the initial analyses. The Equipment is now in place at EML and the necessary testing, calibration and quality control is being performed. This part of the project can provide very important data 
concerning the past integrated radon releases from the silos through radiochemical measurement of the long lived ${ }^{210} \mathrm{~Pb}$ decay product. The actual venting of radon from the silos is very small, and the historic concentrations important. The maximum average quarterly concentration measured on top of the silos in our research was less than $10 \mathrm{pCi} / \mathrm{L}$, and is normally about twice normal outdoor concentrations.

\section{Plans for Next Year:}

Next year the removal of the radium from the silos will commence. The detectors will provide the detailed information concerning radon release. Additional detectors will be placed around the interim concrete storage vault to assure that the entire Fernald site is measured. There are no large sources such as this with a gaseous decay product to study the dispersion models in detail. The current models in use by many investigators, such as the DOE dispersion code ResRad, are being examined to determine whether they provide proper dispersion and dose modeling if the source term is known. In this case the source term at the silos is measured and the environmental radon/ thoron samples provide the actual data to test the models.

The particle size sampler is currently in process of being modified. The new version will have additional fine screen filters to give higher resolution to our particle size spectrum We are working with the company that provides the mold and finished product radon/ thoron detectors. Within the next year, an inexpensive sampler it will be available to any DOE site for size sampling. This is to be encouraged and we are attempting to find the appropriate radiological persons at other sites. Without the size information it is not possible to estimate lung dose with accuracy. The sampler is of consequence for any pollutant not only radioactivity. The method of measurement of the material on the filtration stages can be changed to accommodate the species of interest. Bioaerosols, virus nuisance dust etc. can be sampled over integrated or short term sampling to provide data on the desired pollutant.

\section{Patents:}

A patent application for the 3 chamber radon thoron detector was submitted by NYU with later modification for the 4 chamber version. This should be finalized soon but the patent office is slow.

Titled : A personal radon and thoron detector U.S. Patent Application (June 2000)

\section{Time Line:}

The time line is uncertain as it depends upon the activities at Fernald. Detectors are placed at varying locations at Fernald as the site is modified. The data base of all the measurements is being established so that modeling can begin in early January 2003. Appropriate models are being tested. Among the models commonly used by others is Resrad, and the EPA dispersion models posted on the web. 
The particles size sampler head is being redesigned to accommodate more sampling stages and this should be completed and the new version deployed by June 2003. 


\section{References}

EML. International intercalibration and intercomparison measurements of radon progeny particle size distribution. USDOE, Environmental Measurement Laboratory Report EML-589, July 1997.

HARLEY, NH, P. CHITTAPORN. Long term measurement of indoor and outdoor ${ }^{212} \mathrm{~Pb}$ decay products, with estimates of aerosol particle size. Technology 7:407-413; 2000.

ISRAEL, H. The radon-220 content of the atmosphere. P. 313 in "The Natural Radiation Environment", JAS Adams, WM Lowder eds. University of Chicago Press 1964.

NAS. Health effects from exposure to radon, BEIR VI National Academy Press 1999.

NCRP. Exposure of the Population in the United States and Canada from Natural background Radiation. Report No. 94. National Council on Radiation Protection and Measurements, Bethesda, MD 20814

HARLEY, N.H., B S. COHEN, E. S. ROBBINS. The Variability in Radon Decay Product Bronchial Dose. Environment International. 22; (1996) S959-964.

HARLEY, NH., CHITTAPORN, P., FISENNE, IM., PERRY, P. ${ }^{222}$ Rn decay products as tracers of indoor and outdoor aerosol particle size . J. of Environmental Radioactivity 51:27-35; 2000.

SCHERY, S. Measurement of airborne ${ }^{212} \mathrm{~Pb}$ and ${ }^{220} \mathrm{Rn}$ at various indoor locations within the United States. Health Physics 49: 1061; 1985.

SCHERY, S. Thoron in the environment. J. Air and Waste Management 40: 493; 1990. 